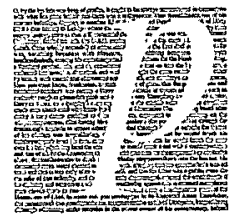

\title{
En el reino de la ambivalencia: \\ la Cuba de Alejandro de Humboldt \\ (Relation historique du Voyage aux Régions équinoxiales du Nouveau Continent) ${ }^{*}$
}

\author{
Oliver Lubrich \\ Universidad Libre de Berlin \\ Instituto de Literatura Comparada
}

Dor lo general, los presuntos textos "no ficcionales," tales como autobiografías, dirección distinta de la biográfico-histórica. En el caso particular de Alejandro de Humboldt, la persona del autor se ha convertido, casi mucho más que su obra, en objeto de amplias investigaciones a partir de las perspectivas más disímiles, pero muy pocas veces a partir de un análisis teórico-literario. Humboldt ha sido visto-y leido-como aventurero, naturalista y político, como historiador, como un hombre de mirada abierta para 'lo ajeno' y un promotor de 'identidades' nacionales, pero casi nunca como literato.

De esta forma no literaria de la recepción tampoco ha quedado exceptuada la obra de Humboldt sobre Cuba, que fue publicada y conocida en forma independiente bajo el título de Essai politique sur l'île de Cuba (Humboldt 1826) y que vio la luz como una

Poligrafias IV (2003) 121-142

(c) Poligrafias. Revista de Literatura Comparada. División de Estudios de Posgrado, Facultad de Filosofia y Letras, Universidad Nacional Autónoma de México, Ciudad Universitaria, México 04510 DF. Tel. (525) 622 1835(6). Fax (525) $6221801 ; 6160047 ; 6221826$. 
sección bastante extensa del libro de viaje Relation historique du Voyage aux Régions équinoxiales du Nouveau Continent (Humboldt 1970). 'Junto con la llamada "Obra de México" (Humboldt 1811), el ensayo político sobre Cuba constituye la única monografia paisológica de Humboldt sobre una colonia española en América. Las estancias de Humboldt en Cuba y la obra sobre la isla que surgió de esas visitas, gozaron en la propia Cuba de un amplio interés. ${ }^{2}$ Es notable el papel de Humboldt en la imaginación colectiva de Cuba, así como en su vida intelectual, ${ }^{3}$ en su historia (Cuevas Díaz 1992, 234-247) asi como en su cultura cotidiana de la actualidad. Humboldt es considerado el "segundo descubridor," un precursor de la independencia nacional, punto de referencia para la revolución social y hasta un punto de partida de la identidad nacional cubana (Bayo 1979). Los aniversarios de Humboldt (el natalicio en 1769, la partida hacia los viajes por América en 1799, la llegada a La Habana en 1801 y 1804, la muerte en 1859) son conmemorados por las instituciones culturales cubanas (Branly 1959) y escenificados por la política cultural alemana para el exterior. ${ }^{5}$

En las siguientes reflexiones la atención deberá centrarse sobre todo en el texto de Humboldt. Para leer el escrito sobre Cuba desde un punto de vista literario, o más bien teórico-literario, es preciso considerar el Ensayo politico sobre la Isla de Cuba no como algo aislado, sino recurriendo a los pasajes correspondientes en el contexto de la Relation historique du Voyage aux Régions équinoxiales du Nouveau Continent. ${ }^{6} \mathrm{~A}$ partir del ejemplo de Cuba será posible estudiar en detalles concretos la confrontación de Humboldt con un país latinoamericano. ¿Qué percepción tiene de Cuba Alejandro de Humboldt? O, mejor aún, ¿cómo describe a Cuba literariamente?, ¿qué papel juega la isla en el conjunto de la obra sobre sus viajes por América?

Se busca responder concretamente a cuatro interrogantes: ¿cómo modela Humboldt la dramaturgia de su acercamiento a Cuba?, ¿cómo escenifica poéticamente su arribo a La Habana?, ¿qué recodificación sufre su terminología durante su estancia en la isla?, ¿qué función simbólico-topográfica asume Cuba en la descripción de sus viajes por América?

\section{1}

Las partes dedicadas a Cuba en el libro de viajes de Humboldt, de cuya sección principal quedó conformado el Essai politique..., no parecen concebidas de manera coherente ni están estructuradas de forma unitaria. ${ }^{7}$ Con una estructura marcadamente heterogénea, el corpus cubano de Humboldt varía, en lo que al género literario se refiere, entre el relato descriptivo del viaje, la descripción científica del país y el ensayo sociopolítico. ${ }^{8}$

Visto a un nivel semántico, el texto de Humboldt, al referirse a Cuba, sufre una dispersión particular. Ya en la descripción de la travesía desde Nueva Barcelona hasta La Habana (III. 322-330), en el proceso de acercamiento espacial y temático de Humboldi a la isla de Cuba emergen una serie de descripciones aparentemente secundarias cuyo subtexto muestra un modo especifico de percepción: durante el viaje por mar, los efectos ópticos engañosos crean la ilusión de una supuesta cercania ("me fait croire que l'éloignement de l'île étoit moins grand que nous ne le supposâmes"/ 
"me parecia que la isla estaba mucho más cerca de lo que suponiamos" III. 323) y de una aparente grandeza ("Les rochers [...] paroissoient beaucoup plus élevés qu'ils ne le sont effectivement" / "Las rocas parecian mucho más altas de lo que eran en realidad" III. 324), lo cual genera una desestabilización de las impresiones y una inseguridad de la percepción.

Al entrar en las aguas cercanas a la costa se acentúa la simultaneidad de experiencias sensoriales opuestas: en el barco predomina un hedor insoportable ("l'odeur de la viande sèche, dont le navire étoit chargé, devenoit encore plus insupportable." / "el hedor de la carne seca que cargaba el barco, se hacía cada vez más insoportable" III. 329), la proximidad de la isla se anuncia sin embargo a través de agradables aromas ("la proximité de l'île de Cuba s'annonçoit par une délicieuse odeur aromatique" / "la cercanía de la isla se anuncia por un olor agradable y aromático" III. 330). ${ }^{9}$ Ya aqui se introduce lo que será el leitmotiv de las descripciones de viaje de Humboldt en Cuba: la pérdida del carácter inequívoco, la polisemia.

La secuencia del acercamiento a Cuba durante la travesía transcurre en las siguientes fases temáticas: mediciones científicas y obra cartográfica, olores, visualización de la isla, entrada en la bahía y percepción de la ciudad de La Habana. La dramaturgia de este pasaje opera con efectos climáticos y anticlimáticos, así como con la ruptura de expectativas construidas mediante recursos artísticos. Desde el punto de vista de la composición del texto, al momento retardador de la travesía (III. 322-330) le sigue el emocionante punto climático de la llegada (III. 330), cuya descripción a su vez es retardada por una serie de estadísticas sobre la población en las Antillas (III. 330-344), hasta que por fin tiene lugar la escena de la entrada en el puerto (III. 348). Sin embargo; desde el punto de vista del estilo, tras el efecto de gradación de la extensa construcción del suspenso que tiene lugar en la pródiga descripción de la travesía, Humboldt coloca la siguiente declaración expuesta en el tono de un desapasionado cronista: "Nous mouillâmes dans le port de la Havane, le 19 décembre, après vingt-cinq jours de navigation par un temps constamment mauvais" / Entramos en el puerto de La Habana el 19 de diciembre, después de 25 dias de travesía a través de un constante mal tiempo" (III. 330).

\section{2}

Una pequeña obra maestra de la literatura la constituye por si misma la descripción de la llegada de Humboldt a La Habana. El viajero describe cómo el barco en que viaja desde Venezuela se acerca a la costa y entra al puerto, y cómo él baja a tierra y se adentra en la ciudad. En el transcurso de esa descripción el texto presenta una doble lectura de la capital cubana. Humboldt observa primeramente: "L'aspect de la Havane, à la entrée du port, est un des plus rians et des plus pittoresques dont on puisse jouir sur le littoral de l'Amérique équinoxiale, au nord de l'équateur." / "La vista de La Habana, a la entrada del puerto, es una de las más alegres y pintorescas de que pueda gozarse en el litoral de la América equinoccial, al norte del ecuador" (III. 348). Una página después, por el contrario, se dice: "A l'époque de mon séjour, peu des villes de l'Amérique espagnole offroient, par le manque d'une bonne police, un aspect plus 
hideux" / "Durante mi estancia en la América española, pocas ciudades de ella presentaban un aspecto miás asqueroso que La Habana, por falta de una buena policia" (III. 349). Estos juicios divergentes se encuentran en dos páginas contiguas (III. 348-349), ambas en el extremo inferior de la página, en dos líneas impresas que se hallan situadas a la misma altura. ${ }^{10}$ ¿Cómo puede explicarse la contradicción de estas dos valoraciones que apuntan en direcciones opuestas pero que se hallan situadas muy cerca una de otra? ¿Cómo explicar el contraste entre una percepción eufórica de La Habana y otra desagradable? ¿Describe Humboldt dos aspectos distintos de la misma ciudad? ¿Cambió sencillamente de parecer? ¿Acaso ha perdido la visión de conjunto sobre su propio texto? ${ }^{11}$

La percepción de Humboldt de la belleza de La Habana (desde el barco) funciona según una estética de hibridación: La Habana le resulta a un tiempo extraña (viaja por primera vez a esa ciudad) y familiar (tanto en su aspecto "ẹuropeo" como "colonial español," la ciudad le recuerda otros paisajes conocidos). Humboldt coloca la capital de Cuba a una cierta y dudosa distancia. Lo que agrada es el contraste, la coexistencia de elementos opuestos: la pintoresca combinación de extrañeza y familiaridad, lo ajeno en lo familiar y lo familiar en lo ajeno o, para decirlo brevemente; el hibridismo, el entrecruzamiento de mundos en un mismo sitio. ${ }^{12}$

Más adelante, Humboldt instala las palmas de los alrededores de la Habana como símbolos botánicos de ese "contraste:" ve en ellas unas plantas que combinan la ternura ("tendre") y la discordia ("fendillé"), columnas ("colonnes") que unen la tierra con el cielo ("qui montent droit vers le ciel" / "que crecen derechas hacia el cielo" III. 350). En las dos fases de su ekphrasis Humboldt se sirve primeramente de la panorámica estática de una descripción impresionista y, luego, del dinámico movimiento del ojo de una cámara en una descripción consecutiva. El ojo del observador se desplaza con creciente flexibilidad. El viajero registra la ubicación de la bahía (desde el barco) y luego (desde cerca) la solidez de las edificaciones, las calles sin empedrar y la estrechez de la ciudad. ${ }^{13}$

A primera vista está la contradicción, o más bien la corrección, de una primera impresión positiva por un segundo juicio negativo, un conflicto entre una vista exterior y una mirada interior, entre una percepción desde lejos y un efecto de cercanía, entre una impresión general y una observación detallada. Desde la distancia del barco que se acerca, La Habana parece hermosísima, "pittoresque" (III. 348), lo que literalmente significa "como una pintura." Lo que, de forma panóptica, idealiza esta visión general abstracta-que en realidad es "teórica"-, es corregido seguidamente por una experiencia detallada concreta, o más exactamente, "práctica." La aproximación del caminante significa a la vez una pérdida de la distancia estética, lo cual imposibilita la visión panorámica. Crea inmediatez, contacto directo, cercanía fisica. Lo que antes era "pictórico" pasa a ser asqueroso, "hideux" (III. 349). Mientras la distancia de observación estética pone de relieve, en primera línea, lo visual, en medio de la ciudad se activan sobre todo los "bajos" sentidos: Humboldt pone en movimiento una sinestesia táctil-olfatoria compuesta de lodo, suciedad, estrechez, aglomeración y olores, y con ellos pone en marcha un proceso de repugnancia que había sido 
introducido con el adjetivo "asqueroso" ("hideux") (III. 349-351). La ciudad es asociada con insalubridad y con enfermedades (III. 359-360). ${ }^{14}$ Después del hedor a bordo, del aroma de la isla todavía invisible y de la magnificencia de la vista al entrar en la bahía, la percepción ha alcanzado aquí su polo negativo absoluto. La mirada de Humboldt experimenta al bajar del barco una transición de la más grandiosa belleza a la más insoportable fealdad.

Las apreciaciones de Humboldt parecen determinar en cada caso una valoración específica de la relación entre naturaleza y cultura. Lo que agrada es una naturaleza que muestra aspectos de civilización; lo que desagrada es una cultura en la que lo natural no ocupa un lugar adecuado y se hace notar más de lo debido. Humboldt observa un proyecto de construcción abandonado, los troncos de árboles previstos para el entramado se pudren en el lodo (III. 349). Al parecer, lo que es bello por naturaleza se derrocha de manera absurda en La Habana sin llegar a transformarse oportunamente en cultura. Humboldt critica una supuesta mala planificación urbanística y apunta incluso algunas propuestas de mejoras en este sentido.

Alejo Carpentier utilizó esos pasajes citados como un motivo de su ensayo sobre la estructura y arquitectura de La Habana: "La ciudad de las columnas" (Carpentier 1982). En este breve texto Carpentier describe las características estilísticas de la capital cubana. El autor cubano rectifica a Humboldt, cuya queja sobre el supuesto "plan de calles mal hecho" en la ciudad vieja toma como punto de partida de sus reflexiones. La tesis principal es la posibilidad, en principio, de interpretar los distintos y llamativos elementos formales a partir de la necesidad de crear espacios de sombra en el calor tropical. ${ }^{15}$ Carpentier analiza cinco motivos por separado: 1) la aparente disposición no planificada de la ciudad vieja como un juego verdaderamente complejo entre la luz y la sombra y como manifestación de un lenguaje de formas específicamente tropical-coloniales; 2) la inmensa abundancia de columnas de diversa índole como un laberinto infinito de paseos con arcadas y columnatas que le posibilitan al transeúnte moverse casi todo el tiempo a la sombra; 3 ) las suntuosas obras de herrería en los enrejados de ventanas y puertas, guardacantones, farolas y separadores, como elementos aislantes que permiten el paso del aire y de la luz a los espacios habitables y que, al mismo tiempo, constituyen medios proveedores de sombra; 4) los multicolores ventanales de medio punto sobre las entradas y patios como medios de refracción, rechazo y matización de la luz solar; y 5) de manera similar, la mampara, que originalmente era una pantalla de madera con revestimiento de tela y luego pasó a ser una puerta interior o intermedia con cristales y motivos pictóricos, como un elemento divisorio en el patio que signa el carácter de la convivencia hogareña y el comportamiento de la comunicación, la "heráldica" y hasta la "ética" de la casa. ${ }^{16} \mathrm{El}$ vocabulario empleado por Carpentier, específicamente el uso de la metáfora de la "heráldica," apunta hacia una interpretación de las características estilísticas de la ciudad de La Habana como elementos de la formación de una identidad cultural. En general, el estilo cubano parece ser una forma específica producida por el genius loci y la transculturación, un orden del desorden aparente, cuya singularidad pudo escapar solamente a un observador superficial como Humboldt. La interpretación de 
Carpentier termina atribuyendo a Alejandro de Humboldt un misreading esencial de la arquitectura y la urbanística de La Habana y, en este sentido, una incomprensión de la realidad concreta latinoamericana.

Mientras que la obra de Humboldt sobre México tuvo una acogida bastante discrepante en ese país, ${ }^{17}$ las voces críticas, como la citada objeción de Carpentier, fueron en Cuba hasta entonces más bien un hecho raro. ${ }^{18}$ Mientras el novelista cubano no iba más allá de constatar y rectificar este concreto malentendido urbanístico de Humboldt, Juan Ortega y Medina, por su parte, desarrolló en un sentido comparable-específicamente en la introducción a la edición mexicana del Essai politique sur le Royaume de la Nouvelle Espagne-una hipótesis general a la que muy bien podemos recurrir para explicar esa específica percepción equivocada. Carpentier calificaba el estilo de La Habana, cuya lógica Humboldt había pasado evidentemente por alto, como un "barroco" especificamente mestizo, un "barroquismo peculiar" (1982, 13).

La tesis de Ortega y Medina plantea que Alejandro de Humboldt no posee ningún concepto del barroco, aunque ese estilo floreció en América Latina mucho antes del viaje de Humboldt (Humboldt 1966, XLI). ${ }^{19}$ El barroco es, desde un punto de vista histórico-cultural y estético, el punto ciego de Humboldt; ${ }^{20}$ de hecho, Humboldt percibia la naturaleza sudamericana, sobre todo la de la selva tropical, como una sobreabundancia caótica y sensorial, como la omnipresencia de una vida salvaje, primigenia, que desde un punto de vista estético sería "compatible" con el barroco. ${ }^{21} \mathrm{~A}$ las culturas americanas, por el contrario--y un ejemplo de ello lo constituyen las ciudades de Venezuela-Humboldt las vio como "clasicistas:" construcciones ortogonales y racionales que agradan precisamente por su regularidad y, como se hizo patente al entrar al puerto de La Habana, por una mezcla proporcionada, equilibrada y estéticamente contrastante, de elementos naturales y artificiales. Humboldt, sin embargo, no posee los instrumentos teóricos necesarios para comprender la estructura "barroca" de La Habana-aparentemente caótica, pero en realidad razonable-como una forma particular de expresión.

La mencionada parte del texto, con su doble codificación, no puede leerse solamente como la identificación de una deficiencia específica de Humboldt, sino que quizás haya que entenderla también como una estrategia retórica bien calculada; más concretamente, como una poetología implícita ( $y$, tal vez, irónica) en la relación de viaje humboldtiana. La pérdida de las preconcepciones idealizadoras en el transcurso del acercamiento y la suspensión de una idealización estética según modelos clasicistas, todo ello como resultado de un contacto directo, apuntan hacia un fenómeno fundamental de la literatura de viaje, tal y como el propio Humboldt la ha practicado y analizado de manera autorreflexiva en las 1682 páginas anteriores de su Relation historique...: la relativización de una estética eurocéntrica mediante la realidad del viaje mismo. Lo que pudo ser idealizado desde lejos, ante el trasfondo de leyes estéticas abstractas, se muestra, al ser observado de cerca, como algo absolutamente contradictorio. 
Salvo en ese sentido implicitamente poetológico y autorreferencial, el pasaje es también significativo desde el punto de vista de la composición: la inversión descrita de una observación eufórica a una peyorativa no concluye en ningún modo en los lodazales de la ciudad vieja. Humboldt contempla La Habana primeramente desde lejos, se aproxima, entra a la ciudad, percibe su fealdad y se evade de nuevo, recobrando espacio libre y una perspectiva central: "Il y a deux belles promenades", proclama Humboldt, "Hay dos paseos muy bellos" (III. 350), que lo conducen fuera del barullo de las calles estrechas. Pero en lugar de hallar aquí, aligerado, una conclusión, el relato culmina en el momento más intenso de desvalorización: Humboldt contempla la venta de esclavos africanos al aire libre (III. 350).

Una lectura estructural del pasaje arrojaría lo siguiente: la escenificación estética de la suciedad y el hedor como ambiente sensorial de un rechazo instintivo prepara la condena moral de la trata de esclavos. La escenificación literaria de la repulsiva ciudad vieja tiene, más que una orientación urbanística, histórico-artística o higiénica, una orientación social, politica y ética. Si lo leemos en el sentido de este subtexto político, no sería casual que Humboldt haya concebido su descripción positiva de La Habana en una terminología geográfica_- "L'aspect... est un des plus rians... de l'Amérique équinoxiale" - mientras el siguiente juicio negativo queda recogido en una terminología colonial - "peu des villes de l'Amérique espagnole offroient... un aspect plus hideux." La repugnancia que provoca La Habana apunta en última instancia a una condena de la esclavitud. En los mismos comienzos del texto sobre Cuba queda establecido el contenido político principal del mismo, el cual hallará su momento culminante en el ensayo final llamado "De la esclavitud." En su aspecto formal, el Essai politique..., como ya se ha indicado, constituye una intrincada trama de narración, libro de divulgación científica y ensayo. Por su contenido, se traza una composición circular que parte de una condena estético-moral de la esclavitud y en cuyo centro se halla un análisis socioeconómico de la misma. ${ }^{22}$

\section{3}

Ya la primera impresión de Cuba y su capital, que quedó preparada por las contraposiciones de motivos en la descripción de la travesía, es doble y contradictoria: belleza y fealdad se confunden. Pero con esta ambigüedad inicial Humboldt plantea el tema central de su obra sobre Cuba no sólo en un sentido poetológico o compositivo, sino también en un sentido semántico: todo en Cuba se torna polisémico, toda la cultura y la civilización, y con ellas también el lenguaje y la terminología de Humboldt.

El colonialismo cubano, tal y como se ofrece a la vista del viajero, se caracteriza por una ambivalencia fundamental: los ya citados bellos paseos ("deux belles promenades" III.350), un teatro ("le théâtre dont l'intérieur a été décoré en 1803 avec beaucoup de goût par un artiste italien" / "el teatro que fue hermoseado en su interior por un artista italiano, en 1803" III. 350) y un jardin botánico ("le jardin botanique" IIl. 350) representan la cultura europea; el comercio de esclavos, por el contrario ("un autre objet, dont l'aspect afflige et révolte à la fois: les baraques devant lesquelles sont 
exposés en vente les malheureux esclaves" / "y otro objeto, cuya vista aflige y choca al mismo tiempo: las harracas delante de las que se ponen en venta los infelices esclavos" III. 350) es representativo de fos crimenes europeos (Schuchard 1999).

Esta doble cara del colonialismo europeo, tal y como se hace visible en Cuba al recién llegado desde el priner momento, también puede verse en la cultura de la memoria oficial: en el mismo sitio donde Humboldt fue testigo de la venta de seres humanos, se erigió después, como el propio Humboldt supo por pesquisas ulteriores, un monumento a Carlos IIl. Humboldt sigue enfatizando la tensión simbólica entre inhumanidad y honra a los héroes que este escenario crea, al reunir asociativamente en ese mismo sitio, en el motivo de una memoria histórica que se materializa en unas concretas "lieux de mémoire." a las figuras centrajes del colonialismo español: el rey, el descubridor y el conquistador. Aquel sitio, escribe Humboldt, habia sido destinado en un inicio para un momunento a Cristóbal Colón, cuyas cenizas habian sido traidas a Cuba el mismo año en que fueron trasladadas a México las de Hernán Cortís para instautar allá un nuevo santuario (III. 350). ${ }^{23}$ Los conceptos eurocéntricos de una filosofia de la historia que confia en el progreso se tornan cuestionables al llegar a este pasaje.

La erosión de una filosofia de la historia de carácter idealista, como causa de la práctica colonial, infecta también la teminologia de Humboldt. A lo largo de todo el texto sobre Cuba podemos observar cómo los conceptos centrales del arsenal filosófico y cientifico de Alejandro de Humboldt adoptan una ambivalencia de enome trascendencia a partir de la drástica vivencia de la economia esclavista. En el espacio de dos páginas, por ejemplo, Humboldt pone de manifiesto la ambivalencia fundamental de su concepto de cultura, cuando habla primero de una "culture intellectuelle" (In. 407) y luego de "la culture du sol" (III. 408), que implica el empleo de esclavos. También el concepto de "colonia" es empleado en una doble acepción, al no usarlo ya solamente como una práctica imperialista de dominación territorial, sino paralelamente tambiér, en un sentido neutral, con el significado de "poblar," como pueden ejercerlowen contra de sll voluntad-los esclavos africanos: "une colonie africaine en Amérique" (111. 597).

En Cuba, los vocablos esenciales de la llustración humanista son insertados en un discurso de carácter económico y se los carga con connotaciones de la economía liberal: "droit" no significa ya solamente un 'derecho' moral o juridico ("acquérir le droit de se dispenser" / "adquirir el derecho a ser liberado" (JS). 446); "I'inégale repartition des droits et des jouissances de la vie" / "el repartimiento desigual de los derechos y de los goces de la vida" III. 446), sino que significa también "impuesto" " tarifa" que se cobra nu sólo por las "mercancias" de tipo material sino tambièn por los seres humanos ("des droits d'entrée" / "el derecho de importación" III. 422; "un droit de 6 piastres par chaque nègre introduit dans l'île" / "un impuesto de seis piastras por cada negro introducido en la isla" Ill. 402).

Asi, de manera muy sutil, toda la dintensión "liberal" de la retórica de Humboldt se toma ambivalente: la palabra "ibre" hay que verla en sentido libertario, el de una libertad entendida como derecho bumano y al mismo tiempo como comercio libre no 
reglamentado, en una acepción de la economía liberal. Es ilustrativo en este sentido el uso realmente provocativo del término en relación con la esclavitud: "le commerce des nègres fut déclaré libre" / "el comercio de negros fue declarado libre"; hoy se diría: ha sido "liberalizado" (II. 403). De manera similar, el término "intérêt," ya no designa solamente el desinteresado afán de conocimiento de la ciencia, sino, por el contrario, significa rédito y rentabilidad ("L'intérêt du capital" / "interés del capital" III. 415). ${ }^{24}$ Se borran los límites entre una percepción aparentemente desinteresada y el explícito interés de lucro en la economía colonial.

También la terminología estética de Humboldt experimenta una recodificación: "vue" es tanto una perspectiva artística ("Vues des Cordillères" / "Vistas de las Cordilleras" II. 319) como un punto de vista político-económico ("Don Francisco Arango, dont les vues ont toujours été pleines de sagesse"/ "Don Francisco Arango, cuyas opiniones han sido tan [...] juiciosas" III. 402); ${ }^{25}$ e incluso el vócablo "tableau," que asumía una función esencial en las descripciones estéticas que hacía Humboldt de la naturaleza, ${ }^{26}$ cambia aquí su significado de 'pintura' por el de 'tabla' o 'lista' ("ces tableaux que l'on publie" / "los estados que se publican" III. 429), ${ }^{27}$ como las que presentan particularmente la proporción de la población africana en Cuba. Las diferencias entre un discurso estético y político-económico se disuelven.

En los tomos II y III de su descripción de viaje Humboldt había implementado distintas metaforizaciones alternativas que se podían interpretar en cada caso de una manera consecuente, las cuales otorgaban al texto una dimensión estética adicional sin llegar a complejidades de carácter retórico. ${ }^{28}$ En su confrontación con Cuba, sin embargo, el texto humboldtiano sucumbe a un complejo juego de ambigüedades al enfrentar entre sí dimensiones metafóricas concretamente distintas de importantes palabras, lo que constituye ambigüedades entre varios discursos: filosofia, estética, economía y política. En términos generales, estas ambigüedades no constituyen particularidades de un uso individual del lenguaje. El texto más bien aprovecha las amplitudes del significado de las palabras mismas. La Relación histórica... de Humboldt parece producir sistemáticamente una superposición de distintos campos lexicos y semánticos de los cuales no es posible afirmar cuál de ellos constituye el "pre-texto" y cuál el "sub-texto." 29

El efecto de esta poética es erosionador y desestabilizador. En los pasajes cubanos de su relación de viaje Alejandro de Humboldt abre un campo semántico que es un campo de batalla entre dos tendencias de la filosofia de la Ilustración europea. La filosofía humanista de la historia con la que Humboldt partió rumbo a América queda desmentida en Cuba a través de la práctica colonial y es desacreditada por las ya insinuantes formas poscoloniales y neocoloniales de explotación económica, razón por la cual adopta una ambigüedad radical en el nivel del lenguaje. En consecuencia, Humboldt parece haber perdido la autoridad sobre su discurso.

La pregunta sobre la intencionalidad de este proceso, no obstante, tendrá que quedar abierta: ¿es intencional o no la ambivalencia de Humboldt respecto a Cuba $?^{30}$ ¿Es posible o no elucidar cuál es la tendencia de su texto? ¿Es disparatado o disperso el sentido? Esta abundancia de ambivalencia, ¿debe atribuirse a una soberanía metódica 
o a la dificultad de Humboldt para comprender la realidad cubana? ¿Funge esta ambivalencia general de la retórica humboldtiana como una estrategia sutil de la autodeconstrucción, o sirve de manera inconsciente para articular como contradicción lo que no se ha comprendido?

En el ensayo llamado "De la esclavitud" (III. 445-458) tiene lugar finalmente, y en parte, una revalorización moral de esos términos, cuya dimensión técnico-económica ha sido apenas presentada. Aquí Humboldt oscila entre un discurso idealista y uno político realista sobre la esclavitud y, en concordancia con ello, entre una argumentación moral (básicamente abolicionista) y una económica (legalista-reformista). La crítica a la esclavitud se articula por tanto en una doble retórica: es por una parte una retórica ilustrada, humanista y ética, y es, por otra parte, cautelosa, moderada y pragmática. El discurso de Humboldt sobre la esclavitud se erige como intermediario entre las facciones de los propietarios y de los abolicionistas (III. 336). El objetivo es la abolición total de la esclavitud, "le dernier but est la cessation de l'esclavage" / "el objetivo es la abolición de la esclavitud" (III. 448), el programa, una evolucionista "affranchissement progressif" / "liberación progresiva" (III. 341) mediante reformas provenientes de arriba y mediante una acción concertada y consensuada, "l'action simultanée des hommes libres"/"la acción simultánea de los hombres libres" (III. 448). La esclavitud, desde el punto de vista metafórico, aparece como una enfermedad curable mediante tratamiento ("remédier au mal" / "remediar el mal" (III. 450) y' no como un mal al que es preciso erradicar mediante intervención quirúrgica. ${ }^{31}$ El propio Humboldt resalta su política de dos caras respecto a la esclavitud-que él intenta legitimar remitiéndose en una ocasión a Simón Bolívar-como "buena" y "provechosa" a un tiempo: "Humaine et prudente à la fois"/ "humana y prudente a un tiempo" (III. 341). ${ }^{32}$

Los escritos de Alejandro de Humboldt sobre Cuba permiten ver en un caso concreto lo que Homi Bhabha ha descrito teóricamente desde una perspectiva "poscolonial" como un fenómeno generalizado: la progresiva "hibridación" del discurso colonial en contacto con la realidad de las colonias (Bhabha 1994, 66-122). ${ }^{33}$

\section{4}

¿En qué relación se encuentran las ambigüedades compositivas, del contenido y del lenguaje que se manifiestan en las descripciones de Alejandro de Humboldt sobre Cuba, con la función simbólica de la isla en la imaginación geográfica del viajero? La topografia simbólica de Alejandro de Humboldt ${ }^{34}$ construye una Europa encerrada en sí misma ("L'Ancien-Monde" / "el Viejo Mundo" II. 200) como espacio de procedencia que se divide sobre todo en tres grandes naciones no claramente jerarquizadas: Alemania, Francia y España. Las Islas Canarias forman un primer espacio intermedio, un prólogo en su condición de microcosmos europeo-americano. El viaje a América propiamente dicho se divide en cinco grandes estaciones, de las cuales hay tres que conforman centros de gravedad inequivocos y claramente delimitados, mientras las dos estancias en Cuba no parecen tener un sitio fijo en esta división: Venezuela (primer centro de gravedad), Cuba (primera estación intermedia), 
los países andinos (segundo centro de gravedad), México (tercer centro de gravedad) y nuevamente Cuba (segunda estación intermedia). En el camino de regreso Humboldt se detiene en los Estados Unidos, que en este caso asumen, como las Islas Canarias, una función complementaria como estación de tránsito entre Europa y Sudamérica. Puede verse asi la estructura simétrica de la composición. Las dos estancias de Humboldt en la isla de Cuba abarcan en total unos tres meses: del 19 de diciembre de 1800 hasta el 15 de marzo de 1801 y del 19 de marzo hasta el 29 de abril de 1804; en ambas ocasiones Humboldt se encuentra, en cierto sentido, de tránsito: primero camino de Venezuela a Colombia y en la siguiente, de México a Estados Unidos.

La posición de Cuba en la topografia imaginativa de Humboldt es intermediaria en diferentes sentidos: La Habana se halla simbólicamente situada entre Europa y América: "La Havane [...] rivalise, par ses ouvrages, avec les places les plus importantes de l'Europe" / "La Habana rivaliza por sus obras con las plazas más importantes de Europa" (III. 407). La extensión de la isla hace a Cuba comparable con Inglaterra (III. 346), su urbanidad eleva a La Habana al rango de las grandes ciudades del mundo. Los cubanos ricos hacen viajes a las metrópolis (III. 407). Humboldt constata incluso una mayor cercanía-lo mismo histórica que geográficamente ficticia-de Cuba ("cette apparence d'une inégalité de distance" / "esta apariencia de una desigualdad de distancia" III. 407) con el viejo mundo y no con el nuevo continente: "la Havane paroissoit dix fois plus rapprochée de l'Espagne que le Mexique, Caracas et la Nouvelle-Grenade" / "La Habana parecia diez veces más cercana a la España que Méjico, Caracas y Nueva Granada" (III. 407).

Como parte no realmente exótica de lo "exótico," Cuba, en el contexto de la descripción de viaje, aparece por tanto de una manera no espectacular:

Despuis que le perfectionnement de l'art du navigateur et l'activité croissante des peuples commerçans ont rapproché les côtes des deux continents, depuis que la Havane, Rio Janeiro et le Sénégal nous paroissent à peine plus éloignés que Cadix, Smyrne et les ports de la Baltique, on hésite de fixer l'attention du lecteur sur un trajet des côtes de Caracas à l'île de Cuba. La Mer des Antilles est connue comme le bassin de la Méditerranée. (III. 322)

Desde que el perfeccionamiento del arte de la navegación y la creciente actividad comercial de los pueblos ha acercado las costas de ambos continentes, desde que La Habana, Rio Janeiro y Senegal casi no nos parecen sitios más lejanos que Cadiz, Esmirna o los puertos del Báltico, uno duda al querer atraer la atención del lector hacia una travesia desde las costas de Caracas hasta la isla de Cuba. El Mar de las Antillas es hoy tan conocido como el Mediterráneo.

En el contexto del imperio colonial hispanoamericano, Cuba asumió desde el punto de vista jurídico administrativo una doble posición especial: si bien la isla fue durante mucho tiempo una colonia de segunda categoría, administrada desde el Reino de la Nueva España ("liées à la métropole mexicaine, alors colonie elle-même de l'Europe" l "unida a la metrópoli mexicana que entonces era colonia de la Europa" III. 347), después de la descolonización en América Central y del Sur continuó siendo la última posesión española en América (III. 346). Su riqueza la distingue del resto de las 
colonias ("Cette île est, de toutes les possessions de l'Espagne, celle qui a le plus prospéré" / "De todas las posesiones españolas, ella es la que más ha prosperado" III. 347); también la distingue su significación internacional como centro del comercio ("le port de la Havane [...] s'est élevée au rang des premières places du monde commerçant" / "el puerto de La Habana [...] ha subido a la clase de plazas de primer orden del mundo comerciante" III. 347). En el contexto de las Antillas, Cuba también constituye un caso excepcional: su larga tradición como lugar de asentamiento y su fuerte identidad nacional-que puede sorprender en un pais que fue dependiente por más tiempo que otros-la distinguen de otras islas y la acercan a las naciones de Europa. Parece que La Habana es al mismo tiempo metrópoli y colonia.

Cuba ocupa un sitio especial en la topografía imaginaria de Humboldt: como frontera geográfica entre la América del Norte y la del Sur, como eslabón imaginario entre América y Europa, como estación intermedia en el viaje de Venezuela a Colombia y de México a los Estados Unidos, como región civilizada en comparación con los paisajes arcaicos de los llanos, de la selva y del Orinoco, como terreno relativamente familiar en medio de lo ajeno, como primera y última posesión española en América y como ejemplar político único entre provincia, colonia y nación independiente. Cuba es el espacio intermedio de Humboldt, un microcosmos de su viaje a América, en el que los más disímiles fenómenos observados parecen sintetizarse y coexistir contradictoriamente.

En el marco de la Relation historique... el fragmento sobre Cuba cobra, en más de un sentido, una significación central. ${ }^{35}$ Las ambivalencias especificas constituyen una característica del discurso de Alejandro de Humboldt sobre la isla de Cuba. El proceso de creciente ambigüedad que Humboldt, a través de un complejo sistema de significaciones múltiples, orquestra en su Essai politique sur l'Île de Cuba y en los otros pasajes cubanos de la Relation historique... - proceso que es preparado por un discreto subtexto surgido durante la travesía por mar y que es introducido en la escena de la llegada a La Habana-tiene lugar mediante un uso extenso y aparentemente sistemático de términos que pueden interpretarse lo mismo en un sentido literal que figurativo y de metáforas que permiten múltiples lecturas; a ellos corresponden, desde el punto de vista del contenido, un discurso político-económico doblemente codificado sobre la esclavitud $y$, espacialmente, una imaginación topográfica que se mueve especificamente "entre dos mundos."

La estancia en Cuba, su confrontación con la isla, conforman al parecer el momento de la Relation historique... en el cual cristalizan las contradicciones del discurso humboldtiano. Desde un punto de vista estético, retórico-temático y simbólico-topográfico, la isla de Cuba constituye el reino de la ambivalencia de Alejandro de Humboldt.

Traducción de Aníbal Campos

\section{Notas}

'Ésta es una nueva edición íntegra del original publicado en París entre 1814 y 1825. En adelante las citas se harán a partir del original francés (Relation historique...). 
Los números tomanos indican en el texto el tomo, los números arábigos indican la página correspondiente. La portada se refiere al año 1825 como fecha de publicación del tercer tomo; sin embargo, la fecha más tardia que se menciona en el texto es "octobre 1830" (III. 596), de modo que el cierte de la publicación se supone sea 1831. La Relation historique... describe, según la cronología, la primera estancia de Alejandro de Humboldt y Aimé Bonpland en Cuba e incluso esto lo hace de una manera en extremo breve, en el sentido de una presentación narrativa coherente, pues la mayor parte la ocupa el texto de carảcter paisológico y ensayístico. La segunda estancia en Cuba resulta absolutamente imposible de reconstruir a partir de los diarios conservados, que, por lo demás, incluyen detalladas descripciones de la mayoría de las partes referentes a todo el transcurso del viaje; los diarios se encuentran hoy, en su versión original, en el Departamento de Manuscritos de la Biblioteca Estatal de Berlín (Oeste). El Centro de Estudios Alexander von Humboldt de la Academia de Ciencias en Berlín (antigua RDA) realizó una copia tipográfica. Fragmentos de las partes del viaje de Humboldt después de su llegada a Colombia, no recogidos en la relación de viaje, fueron publicados como: 1986/1990. Reise auf dem Rio Magdalena, durch die Anden und México. 2 tomos [1: textos, 2: traducciones]. Ed./trad. Margot Faak. Berlin/RDA: Akademie-Verlag. Esta selección comienza con la salida desde Cuba rumbo a Cartagena (tomo $1,41-56$ ) y termina con la travesía desde Veracruz hacia Filadelfja, pasando por La Habana (tomo 1, 394-395).

${ }^{2}$ La primera edición en español de la obra sobre Cuba apareció un año después del original francés: 1827. Ensayo político sobre la Isla de Cuba, por el Barón A. de Humboldt, con un mapa. Trad. D. J. B. de V. y M. París: Jules Renouard. En Cuba se publicó la edición al cuidado de Fernando Ortiz en el año 1930: Ensayo político sobre la Isla de Cuba, por Alejandro de Humboldt, con un mapa de Cuba. Introducción por Fernando Ortiz y correcciones, notas y apéndices por Francisco de Arango y Parreño, J. S. Thrasher y otros. La Habana: Colección de libros cubanos. El texto fue reeditado varias veces después del triunfo de la Revolución Cubana: Alejandro de Humboldt. 1959. Ensayo político sobre la Isla de Cuba. Homenaje de la ciudad de La Habana en el centenario de su muerte. La Habana: Oficina del historiador de la ciudad de la Habana; Alejandro de Humboldt. 1959. "Ensayo político sobre la Isla de Cuba." Revista Bimestre Cubana 76: 190-451; Alejandro de Humboldt. 1960. Ensayo político sobre la Isla de Cuba. Nota preliminar por Jorge Quintana Rodríguez, introducción por Fernando Ortiz. La Habana: Publicaciones del Archivo Nacional de Cuba; ver la actual nueva edición: Alejandro de Humboldt. 1998. Ensayo político sobre la Isla de Cuba. Ed. Daniel García Santos, introducción biobibliográfica de Fernando Ortiz, correcciones, notas y apéndices de Francisco de Arango y Parreño, J. S. Thrasher y otros. La Habana: Fundación Fernando Ortiz. Sobre la historia de las ediciones, ver Ulrike Leitner, "Las obras de Alejandro de Humboldt sobre Cuba" (Họll 1997, 51-60); sobre la historia de las ediciones y la repercusión, ver también Hanno Beck (1992, 227-264). Esta edición contiene la traducción alemana del "Essai politique sur l'lle de Cuba" (III. $345-458=$ pp. 5-169), así como la traducción alemana incompleta de algunos de los "Additions," "Apéndices" (IIl. 580-613 = pp. 170-226, los textos pp. 
170-207, las estadísticas, pp. 208-226). Ver también Charles Minguet, "Un livre fondateur: L'Essai politique sur l'Île de Cuba, de Alexandre de Humboldt" (Humboldt 1989, I-III), Jean-Paul Duviols, "Les images anciennes de Cuba" (Humboldt 1989, V-VI) y Jeanine Potelet, "Le seconde découverte de Cuba: L'Essai politique de Alexandre de Humboldt" (Humboldt 1989, VII-XXX).

${ }^{3}$ En la Universidad de La Habana existe, paralelamente a la carrera de Germanística e idioma alemán, una institución autónoma: la Cátedra Alexander y Wilhelm von Humboldt. En 1999, el año de Humboldt y bicentenario de su llegada a América, se inauguró en el casco histórico de La Habana una casa restaurada con apoyo de Alemania, en la que Humboldt residió y a la que se dio el nombre de "Casa Humboldt."

${ }^{4}$ La creación del epiteto "segundo descubridor" se atribuye generalmente al cubano José de la Luz y Caballero (1800-1862) y es una variación de una frase de Simón Bolívar que calificaba a Humboldt como el "verdadero descubridor" de América; es la frase que aparece en la inscripción en la base de la estatua de Humboldt frente a la universidad berlinesa que lleva su nombre; ver Ingo Schwarz, "Acerca de la historia de la dedicatoria 'Al segundo descubridor de Cuba. La Universidad de La Habana, 1939' en el monumento a Alejandro de Humboldt en Berlín" (Holl 1997, 103-109).

${ }^{5}$ Ver Andreas Hoetzel, "Cubas liebster Deutscher. Alexander von Humboldt: auf Castros Insel unvergessen," documental, Alemania 1999 (transmitido por "Phoenix" televisión el 28 de julio de 1999); ver Christine Backhaus. 1999. Auf Humboldts Spuren. Der Südamerika/Karibik-Törn der Bark 'Alexander von Humboldt' 1998/1999. Bremerhaven: DSST.

${ }^{6}$ La relación de viaje ha tenido hasta la fecha muy escasa recepción en su versión original y ha sido incluso poco usada en trabajos de carácter científico. Particularmente en el ámbito de habla alemana, un sinnúmero de ediciones traducidas, reducidas y adaptadas han enmascarado el original francés (Ette 1996).

${ }^{7}$ La parte de la relación de viaje que tiene como objeto la primera estancia de Humboldt en Cuba se extiende a lo largo de los capítulos XXVII, XXVIII y XXIX del tercer tomo. Está estructurada de la siguiente forma: el capítulo XXVII (III. 322-344) describe el viaje en barco desde Cumaná, en Venezuela, hasta La Habana. El capítulo XXVIII (III. 345-483) contiene el Essai politique sur l'Ile de Cuba propiamente dicho (III. 345-458), que a su vez está subdividido en distintas secciones paisológico-temáticas, dedicadas a una introducción con consideraciones generales (III. 345-348), a la capital, La Habana (III. 348-362), a la extensión y el clima (III. 362-387), a la población (III. 387-408), la agricultura (III. 408-428), el comercio (III. 428-440) y la hacienda (III. 441-445), e incluye el ensayo sobre la esclavitud (III. 445-458). Al final se retoma la narración del viaje (III. 458-483) y le siguen a continuación las notas a ese capítulo (III. 484-501). El capítulo XXIX (III. 502-579) contiene la descripción de la partida de Cuba y la travesía hasta la ciudad de Cartagena, así como el inicio de la relación sobre la estancia de Humboldt en la actual Colombia. La parte principal de la relación de viaje se interrumpe aquí inesperadamente (III. 579). Al final del tercer tomo, que constituye también el final de toda la Relation historique..., se encuentran algunos Apéndices ("Additions" III. 580-629). Estos se 
dividen en: 1. una "Géographie astronomique de l'lle de Cuba" (III. 580-592) y 2. diversas "Tableaux statistiques de l'lle de Cuba pour les annés 1825 et 1829" (III. 592-614), que incluyen abundante material estadístico en tablas sobre la demografia de Cuba (4 páginas dobles entre III.613 y III.615), antes de que, finalmente, la publicación fragmentaria concluya de manera poco espectacular con una tercera sección de "Observations d'inclinaison et d'intensité des forces magnétiques," observaciones sobre amplios valores internacionales registrados acerca del magnetismo de la tierra (III. 615-627), y finaliza con un último apéndice epitextual, una "Note supplémentaire à la description des petits volcans de Tubaco (vol. III, p. 561-567)" (III. 627-629), que remite nuevamente al viaje de Humboldt por Colombia.

${ }^{8}$ Incluso fuera de los marcos de la obra sobre Cuba, la isla juega, en distintos sentidos, un papel en la relación de viaje: antes de describir la (primera) estancia de Humboldt en Cuba, aparece La Habana en un pasaje que consiste en una curiosa y aparentemente arbitraria analogía con Río de Janeiro, en el contexto de una observación comparativa de las regiones equidistantes del ecuador a la altura de los trópicos (III.304). La isla de Cuba es mencionada primero en dos ocasiones, siempre en relación con la población de esclavos africanos (III. 58, III. 66). Además de los Diarios y de la Relation historique... hay otros capítulos científicos en la obra de Humboldt sobre América que se refieren a Cuba en distintas formas: a plantas recién descubiertas allí (1815-1825. Nova genera et species plantarum. 7 tomos. París: Libraria Graeco-Latino-Germanica), a mediciones astronómicas de los lugares (1808-1811. Recueil d'observations astronomiques, d'opérations trigonométriques et de mesures barométriques, faites pendant le cours d'un voyage aux régions équinoxiales du Nouveau Continent, depuis 1799 jusqu'en 1803. 2 tomos. París: F. Schoell) y a la historia geográfica y del descubrimiento de la isla (1836-1839. Examen critique de l'histoire de la géographie du Nouveau Continent et des progrès de l'astronomie nautique aux quinzième et seizième siècles. 5 tomos. París: Librairie de Gide).

"Ottmar Ette interpreta este pasaje, el topos de la "isla aromática," como una reescenificación ficcional de la percepción de Cuba en Cristóbal Colón: Ottmar Ette, "'Si yo mintiese al igual que todos los cronistas de viajes,' Alejandro de Humboldt y Colón" (Holl 1997, 61-73; aqui 65); ver, del mismo autor, "Entdecker über Entdecker: Alexander von Humboldt, Cristóbal Colón und die Wiederentdeckung Amerikas" (Ette 1992).

${ }^{10}$ Como sucede en la mayoría de los autores, Fernando Ortiz no aborda en su introducción de 84 páginas aquellas impresiones, notoriamente contrastantes, de Humboldt sobre La Habana, y cita la primera descripción eufórica en la paráfrasis de un historiador cubano (Vidal Morales, en "El Figaro" 1897); Fernando Ortiz, "Introducción biobibliográfica" (Humboldt 1998, XIII-XCIX; aqui, XXVIII-XXIX). Otto Olivera señala brevemente esta contradicción (1998, 41-47). Sobre Fernando Ortiz, ver Miguel Barnet/Alberto Quesada, "Alejandro de Humboldt (1769-1859) y don Fernando Ortiz (1881-1969); dos sabios descubridores de Cuba," (Holl 1997, 75-82). 
"Entre todos los momentos de la relación de viaje, el que menos puede ser leído como una descripción realista de hechos es el de la llegada a un "nuevo" país. La llegada es por lo general un momento ritualizado en alto grado (por ejemplo, la descripción de Humboldt de su llegada a las Islas Canarias, a Cumaná, etc., o la célebre descripción de Georg Forster sobre su llegada a Tahiti (Georg Forster 1983, 241 y siguientes).

${ }^{12}$ Un papel esencial como topo de la percepción lo jugaba el contraste sobre todo en aquellos pasajes del primer tomo de la relación de viaje que describen la llegada de Humboldt a Venezuela. Allí Humboldt desarrolla una verdadera estética y una epistemología del contraste. Se registra aquello que contrasta en sí mismo y lo que, además, contrasta con lo propio. El viajero soluciona el problema de la coexistencia de caracteristicas contradictorias de lo ajeno y hace de la necesidad una virtud: el modo más simple de tratar con estados de cosas opuestos es su contraste reconciliador. Lo extraño se percibe a partir de sus contrastes.

${ }^{13}$ Humboldt llega a generalizar su juicio de tal modo que describe la estrechez insular de Cuba, "les limites étroites d'une île" (III. 325) como un factor negativo.

${ }^{14}$ Los editores de la nueva edición española del Essai politique sur l'lle de Cuba interpretan esta percepción negativa de Humboldt de la ciudad de La Habana desde cerca, en el contexto de su interés médico por el fenómeno de las epidemias: Miguel Angel Puig-Samper, Consuelo Naranjo Orovio y Armando García González, "Estudio introductorio: Alejandro de Humboldt y la Isla de Cuba" (Humboldt 1998a, 17-98; aquí 72). Desde el punto de vista histórico, la descripción de Humboldt sobre La Habana podría interpretarse dentro del discurso sobre la higiene investigado por Alain Corbin, como una política de "desodorización" que acompaña a una sensibilidad olfatoria acrecentada (Corbin 1982).

15 "Humboldt se quejaba, en su tiempo, del mal trazado de las calles habaneras. Pero llega uno a preguntarse, hoy, si no se ocultaba una gran sabiduría en ese 'mal trazado' que aún parece dictado por la necesidad primordial-tropical-de jugar al escondite con el sol..." (Carpentier 1982, 11-12).

16 "La mampara participaba del moblaje, de la decoración interior, de la heráldica, y hasta de la ética de la mansión" (Carpentier 1982, 67).

${ }^{17}$ La obra sobre México tuvo en ese país una recepción mucho más polémica que la obra sobre Cuba en la isla caribeña. Como ejemplos de lecturas de carácter polémico-critico y, a la inversa, de una lectura afirmativa de la obra de Humboldt sobre México, es preciso mencionar los trabajos de Juan Ortega y Medina y de Enrique Krauze: Ortega y Medina (Humboldt 1966, IX-LIII) describe a Humboldt como un agente imperialista al servicio de los intereses de Estados Unidos, le reprocha superficialidad científica y escaso talento literario, le atribuye una incomprensión fundamental de la realidad hispanoamericana y critica la instrumentalización de la imagen humboldtiana de México que, en ese sentido, han hecho las élites criollas. Krauze (1994, 21-24), por el contrario, lee a Humboldt desde la perspectiva que le ofrecen las teorías de Octavio Paz como guía para una confrontación crítica con el pasado 
mexicano, para una apertura y una modernización espirituales, así como para una determinación positiva de la identidad propia. Ver también José Miranda (1995).

${ }^{18}$ En su amplia introducción a la edición cubana del Ensayo político sobre la Isla de Cuba, Fernando Ortiz menciona en efecto distintos puntos posiblemente críticos ("defectos," Humboldt 1998, LXXVIII) de una recepción cubana de Humboldt, pero de inmediato los desactiva en su mayoría mediante relativizaciones y legitimaciones de carácter histórico: el apoyo de Humboldt - motivado por una actitud humanitaria -al expansionismo norteamericano no sólo en México, sino también en Cuba (LXXXII), "el anexionismo de Humboldt" ( LXXXIII), "Esto parece una antinomia de Humboldt. ¿Ser liberal y desear la anexión de unos territorios más a los Estados Unidos, y precisamente los de su querido México?" (LXXXIII); la supuesta participación de Humboldt en una intriga franco-prusiana contra Carlos Marx en el año 1845, tal y como afirmaba, además de Federico Engels, el socialista nacido en Cuba (!) y yerno de Marx, Paul Lafargue (LXXII); la subestimación de Humboldt-sobre la que más tarde el propio barón volvería a reflexionar-del beneplácito popular a la causa independentista latinoamericana ( $\mathrm{XXXIV}, \mathrm{XC}$ ) y su errónea valoración de los "libertadores" potenciales (LXXV); las concesiones políticas del cientifico en el trato con las élites del Ancien Régime (LXXVI) _- "ayudar al progreso del liberalismo utilizando las mismas fuerzas absolutistas" (LXXVIII); la supuesta arrogancia de Humboldt (LXII); así como un presunto descuido de la forma literaria (LXXVII)Como ejemplo de una reciente crítica histórico-política más diferenciada, ver Rodrigo Quesada Monge (1999, 5-15).

${ }^{19}$ Ver también F. Mateos (1959, 301), citado por Ortega y Medina.

20 Fernando Ortiz, al contrario, ha intentado incluso explicar la literatura de Humboldt a partir de un impulso progresivo y antibarroco: "Humboldt supo librarse del ambiente literario de su época, muy entregada aún a los estofados y encaracolamientos del gusto barroco" (Humboldt 1998, LXXVII).

${ }^{21}$ Sobre todo en las descripciones de los llanos y de la selva tropical, es posible observar paralelos motívicos y estilísticos entre Humboldt y algunos autores de "lo real maravilloso" o del "realismo mágico," tales como, por ejemplo, Alejo Carpentier ("estilo barroco") o Rómulo Gallegos (Carpentier 1996, Gallegos 1985); ver David Hernández (1996) y Charles Minguet (1986).

${ }^{22}$ Para una interpretación de inspiración marxista del Essai politique... ver Christiane Bimberg (1984). Sobre la creciente importancia del elemento africano en la formación de la identidad cubana, ver Robert Held (1978).

${ }^{23}$ La nueva edición cubana del Ensayo politico... incluye aquí una nota del editor norteamericano Thrasher que corrige la descripción de Humboldt: Las cenizas de Colón fueron traidas a La Habana en 1796 y guardadas allí en la Catedral; las cenizas de Cortés fueron trasladadas ya en 1794 de la iglesia de San Francisco a la de Jesús Nazareno (Humboldt 1998, 8-9). Las asociaciones históricas de Humboldt son por lo tanto buscadas. Por lo demás, sus indicaciones sobre lugares parecen ser correctas. (La apariencia de una continua pérdida de la orientación en el casco histórico de La Habana, que las descripciones de Humboldt dejaron no sólo en Alejo Carpentier, no 
pueden ser verificadas concretamente). Las investigaciones históricas del presidente de la Cátedra Humboldt de La Habana, Iván Muñoz, a quien debo agradecer sus indicaciones en este sentido, han arrojado que Humboldt localizó correctamente el Paseo Extramuros y el Monumento a Carlos III (que fue reubicado con posterioridad). Como en la época de la estancia de Humboldt había muchos sitios en La Habana destinados a la venta de esclavos, y como hasta ahora no han podido ser identificados los restos de aquellas "baraques" en las cercanías del Jardín Botánico, no se puede descartar al menos la posibilidad de que Humboldt también haya forzado literariamente la coincidencia descrita sobre el culto de la memoria oficial colonial con la inhumanidad inherente al sitio destinado al comercio de esclavos.

${ }^{24}$ El significado económico de la palabra "interés" es ciertamente el original y ya aparece registrado así en el siglo XIII (Littré 1956-1958, entrada: "intérêt"). No es posible generalizar y decir que los contenidos de significado "económicos" de los conceptos usados por Humboldt en el ensayo sobre Cuba puedan ser agrupados enteramente en un estrato histórico linguístico más reciente.

${ }^{25}$ Unos 40 conceptos sufren manifestaciones de ambigüedad parecidas en las partes cubanas de la relación de viaje humboldtiana.

${ }^{26}$ Ver la descripción del concepto de la contemplación estético-científica de la naturaleza en el motivo del "cuadro de la naturaleza" ("Naturgemälde") en Ansichten der Natur (Humboldt 1992), sobre todo la Introducción a la primera edición de 1808 (pp. 5-6) y la Introducción a la segunda y tercera ediciones de 1826 y 1849 (7-10).

${ }^{27}$ En el caso de esta acepción se trata, desde un punto de vista de la historia del lenguaje, de una innovación contemporánea, cuyo surgimiento se puede incluso fijar con toda seguridad en la época entre el regreso de Humboldt a Europa y la publicación del Essai politique..., es decir en el año 1812 (Le Robert. Dictionnaire de la langue française 1985, entrada: «tableaux »).

${ }^{28}$ El paisaje de los llanos, por ejemplo, Humboldt lo agrupa en diversos registros metafóricos: pintura, arquitectura, teatralidad, aristocracia, antropomorfia, náutica, geometría, etc. La metaforicidad de las descripciones queda entretanto más o menos visible en texturas relacionadas entre sí.

${ }^{29} \mathrm{La}$ competencia de distintos niveles de significado en el texto de Humboldt puede describirse en el sentido de los análisis de Paul de Man sobre el potencial "deconstructivo" de la "figuralidad" o la "retoricidad,"sobre todo en las "Alegorías de la lectura" (de Man 1979).

${ }^{30}$ Margot Faak señala que los juicios bienintencionados de Humboldt sobre la sociedad cubana en la-posteriormente redactada-Relation historique... ("einen schärferen Blick für den Zustand der Kolonien und der Metropole in Havana" / "una mirada más aguda para el estado de las colonias y de la metrópoli en La Habana" I.590f., "in keinem Teil Spanisch-Amerikas hat die Zivilisation eine europäischere Physiognomie gewonnen." / "en ninguna otra parte de la América española ha cobrado la civilización una fisionomía más europea" IIl.407f.), se apartan de la redacción espontánea de los diarios ("wenig interessant, als wir nun aus Mexico 
anreisten" / "poco interesante, ahora que acabamos de llegar de México") (Faak 1996, 940).

${ }^{31}$ Independientemente del pragmatismo con que siempre fue presentado, el ensayo de Humboldt sobre la esclavitud, en su tendencia abolicionista, fue siempre entendido por la facción de los esclavistas norteamericanos como un texto tan subversivo, que el editor de la edición inglesa lo eliminó sin vacilar, lo que le trajo como resultado la conocida y vehemente protesta de su autor (Humboldt 1856). Ver también el ensayo preliminar de J. S. Thrasher (Humboldt 1998, 309-356) y la respuesta de Humboldt a Thrasher $(1856,4)$. Ver también Consuelo Naranjo Orovio, "Humboldt en Cuba: reformismo y abolición" (Puig-Samper 2000, 183-201).

${ }^{32}$ El Essai politique sur l'lle de Cuba termina en general con una nota optimista sobre la esclavitud, la cual tiene una motivación de orden pragmático. El motivo son las "concessions," la última palabra, sin embargo, es "humanité:" "La crainte du danger arrachera des concessions que réclament les principes éternels de la justice et de l'humanité." / "El temor ante el peligro acarreará concesiones que reclaman los principios eternos de la justicia y la humanidad." (III. 483).

${ }^{33}$ Homi Bhabha desarrolla una teoría postcolonial de la cultura en general y de la discursividad colonial en particular, a partir de una perspectiva postestructuralista. Bhabha describe elementos del discurso colonial en su textualidad, retoricidad y temporalidad, como "écriture," representación iterativa, significancia inestable, y constata siempre la ambiguedad de los significantes coloniales, "the ambivalence of colonial cultural texts" $(1994,119)$ : "[I]n the very practice of domination the language of the master becomes hybrid." / A través de la práctica de dominación, la lengua de los que dominan se torna hibrida (33).

${ }^{34}$ Sobre la dimensión científico-geográfica del "Essai politique...," ver Hanno Beck, "La obra sobre Cuba de Alejandro de Humboldt como fuente de conocimiento" (Holl 1997, 37-50).

${ }^{35}$ El tratamiento de las estancias cubanas de Humboldt en la literatura biográfica es, por el contrario, significativamente escaso. En todo caso, se cita más detalladamente el ensayo de Humboldt sobre la esclavitud, en relación a valoraciones de carácter general sobre el humanismo de Humboldt (Beck 1959/1961, 1: 173-177 y 223-224; Beck 1959, 193-198 y 293-294; Biermann 1990, 43-46 y 49-50; Meyer-Abich 1995, 85-86; Botting 1993, 173-175 y 196; Rübe 1988, 109-111; Schleucher 1988, 66 y 72-73; Schleucher 1984, 180-181 y 196; Scurla 1982, 145-148 y 172-182; Banse 1953, 63; Kellner 1963, 51; Günther 1990, 67-68; Bitterling 1959; Biermann/ Jahn/Lange 1968, 26-27 y 30; Gascar 1985, 112-116 y 134; Duviols y Minguet 1994, 45; Krätz 2000, 72-74 y 125-127; Beck y Schoenwaldt 1999, 38).

${ }^{36}$ Objeto de otra investigación podría ser indagar en qué medida las estrategias analizadas en el texto de Humboldt han hallado resonancia o contraste en otras relaciones de viaje u obras paisológicas comparables, especialmente sobre Cuba, a partir, por ejemplo, de los textos de Joseph J. Dimock (1998) y de Olivera (1998, 17-39). 


\section{Obras citadas}

Banse, Ewald. 1953. Alexander von Humboldt, Erschliessung einer' neuen Welt. Stuttgart: Wissenschaftliche Verlagsgesellschaft.

Bayo, Armando. 1970. Humboldt. La Habana: Editorial de ciencias sociales.

Beck, Hanno. 1959/1961. Alexander von Humboldt. 2 tomos. Wiesbaden: Franz Steiner Verlag.

-1959. Alexander von Humbolts Amerikanische Reise. Wiesbaden: Thienemann.

_._. 1992. "Kommentar. Zu dieser Ausgabe des Cuba-Werkes Erläuterungen zu den Testen." Alexander von Humboldt, Cuba-Werk. Tomo III. Darmstadt: Wissenschaftliche Buchgesellschaft.

___ y Peter Schoenwaldt. 1999. "Der letzte der GroBen." Alexander von Humboldt. Konturen eines Genies. Bonn: Inter Nationes.

Bhabha, Homi K. 1994. The Location of Culture, Londres: Routledge.

Biermann, Kurt R. 1990. Alexander von Humboldt. Leipzig: BSB B. G. Teubner.

- e Ilse Jahn y Fritz G. Lange. 1968. Alexander von Humboldt. Chronologische

Übersicht über wichtige Daten seines Lebens. Berlín/RDA: Akademie-Verlag.

Bimberg, Christiane. 1984. "El 'Ensayo político sobre la Isla de Cuba' de Alejandro de Humboldt como ejemplo de literatura sobre viajes a principios del siglo XIX." Alejandro de Humboldt. Ed. Manuel Lorenzo. La Habana: Conferencias y estudios de Historia y Organización de la Ciencia. 23-42. [Trabajos leídos el 2 de marzo de 1984 en la sesión científica en conmemoración del 125 Aniversario de la Muerte de Alejandro de Humboldt, celebrada en el Centro de Estudios de Historia y Organización de la Ciencia Carlos J. Finlay de la Academia de Ciencias de Cuba.]

Bitterling, Richard. 1959. Alexander von Humboldt (Lebenswege in Bildern). Ed. Ernst Hermann. Munich y Berlin: Deutscher Kunstverlag.

Botting, Douglas. 1993. Alexander von Humboldt. Biographie eines grossen Forschungsreisenden. Trad. Annelie Hohenemser. Munich: Prestel.

Branly, Miguel A. 1959. "Presencia de Humboldt en Cuba." Revista Bimestre Cubana de la Sociedad Económica de Amigos del Pais 76: 7-50.

Carpentier, Alejo. 1982 [1964]. La ciudad de las columnas. La Habana: Editorial Letras Cubanas.

-. 1996 [1953]. Los pasos perdidos. Buenos Aires: Losada.

Corbin, Alain. 1982. Le Miasme et la Jonquille. L'odorat et l'imaginaire social aux XVIIle-XIXe siècles. París: Editions Aubier Montaigne.

Cuevas Díaz, Carmen. 1992. "Presencia de Alejandro de Humboldt en la historia de Cuba." Alexander von Humboldt und das neue Geschichtsbild von Lateinamerika. Eds. Michael Zeuske y Bernd Schröter. Leipzig: Leipziger Universitätsverlag. 234-247.

De Man, Paul. 1979. Allegories of Reading. Figural Language in Rousseau, Nietzsche, Rilke and Proust. New Haven y Londres: Yale University Press.

Duviols, Jean-Paul y Charles Minguet. 1994. Humboldt, savant-citoyen du monde. Paris: Gallimard. 
Dimock, Joseph J. 1998. Impressions of Cuba in the Nineteenth Century. The Travel Diary of Joseph J. Dimock. Ed. Louis A. Pérez. Wilmington: Scholarly Resources.

Ette, Ottmar. 1992. "Entdecker über Entdecker: Alexander von Humboldt, Cristóbal Colón und die Wiederentdeckung Amerikas." Columbus zwischen zwei Welten. Historische und literarische Wertungen aus fünf Jahrhunderten. Ed. Titus Heydenreich. Frankfurt am Main: Vervuert. 401-439.

_. 1996. "Von Surrogaten und Extrakten: Eine Geschichte der Übersetzungen und Bearbeitungen des amerikanischen Reisewerks Alexander von Humboldts im deutschen Sprachraum." Deutsche in Lateinamerika- Lateinamerika in Deutschland. Eds. Karl Kohut; Dietrich Briesemeister y Gustav Siebenmann. Frankfurt am Main: Vervuert. 98-126.

—_ y Walther L. Bernecker (eds.). 2001. Ansichten Amerikas. Neuere Studien zu Alexander von Humboldt. Frankfurt am Main: Vervuert.

Faak, Margot. 1996. Alexander von Humboldt auf Kuba, Berlin: Alexander von Humboldt-Forschungsstelle.

Forster, Georg. 1983. Reise um die Welt (Viaje alrededor del mundo). Ed. Gerhard Steiner. Frankfurt am Main: Insel.

Gallegos, Rómulo. 1985 [1935]. Canaima. Bogotá: Oveja Negra.

Gascar, Pierre. 1985. Humboldt l'explorateur. París: Gallimard.

Günther, Siegmund. 1990. "A. v. Humboldt." A. v. Humboldt. L. v. Buch. Biographieen [sic]. Berlín: Ernst Hofmann \& Co.

Held, Robert. 1978. "Anregungen für Fidel Castro. Alexander von Humboldt und Cubas afrikanische Berufung." Frankfurter Allgemeine Zeitung. 12 de agosto 1978.

Hernández, David. 1996. "Alexander von Humboildt, die andere Suche nach El Dorado. Die 'Reise in die Äquinoktial-Gegenden des Neuen Kontinents' als Vorbote des lateinamerikanischen Romans."Alexander von Humboldt- die andere Suche nach El Dorado und weitere Essays zur zeitgenössischen lateinamerikanischen Literatur. Londres: The World of Books. 6-42.

Holl, Frank Holl (ed.) 1997. Alejandro de Humboldt en Cuba. Augsburg: WiBner.

Humboldt, Alexander von. 1811. Essai politique sur le Royaume de la Nouvelle Espagne. Paris: F. Schoell.

—. 1826. Essai politique sur L'Ile de Cuba. París: Libraire de Gide Fils.

- 1856. The Island of Cuba. Trad. del español, notas y ensayo preliminar de J. S. Thrasher. Nueva York: Derby \& Jackson.

- 1856. "Respuesta de Humboldt a Thrasher." Berlinische Nachrichten von Staats- und gelehrten Sachen 172.

- 1989. Essai politique sur l'île de Cuba. Ed. Charles Minguet, Amos Segala y Jean-Paul Duviols. Nanterre: Éditions Erasme.

-1992. Ansichten der Natur. Ed. Adolf Meyer-Abich. Stuttgart: Reclam.

- 1966. Ensayo politico sobre el Reino de la Nueva España. Trad. Vicente González Arnao, estudio preliminar de Juan A. Ortega y Medina. México: Editorial Porrúa. IX-LIII. 
- 1970. Relation historique du Voyage aux Régions équinoxiales du Nouveau Continent. Fait en 1799, 1800, 1801, 1802,1803 et 1804 par Al. de Humboldt et A. Bonpland, rédigé par Alexandre de Humboldt. 2 tomos. Ed. e intr. de Hanno Beck. Stuttgart: Brockhaus.

—. 1998. Ensayo político sobre la Isla de Cuba. Ed. Daniel García Santos, introducción biobibliográfica de Fernando Ortiz; correcciones, notas y apéndices de Francisco de Arango y Parreño, J. S. Thrasher y otros. La Habana: Fundación Fernando Ortiz.

- 1998a. Ensayo politico sobre la Isla de Cuba. Madrid y Valladolid: Ediciones Doce Calles.

Kellner, Lotte. 1963. Alexander von Humboldt. Londres, Nueva York y Toronto: Oxford University Press.

Krätz, Otto. 2000 [1997]. Alexander von Humboldt. Wissenschaftler-Weltbürger-

Revolutionär. Munich: Callwey.

Krauze, Enrique. 1994. "Humboldt y México: un amor correspondido." Vuelta 18: 212. 21-24.

Littré, Émile. 1956-1958. Dictionnaire de la langue française. 7 tomos. París: Jean Jacques Pauvert.

Mateos, F. 1959. "Viaje de Humboldt a la América Española." Razón y Fe 160-161. 301.

Meyer-Abich, Adolf. 1995. Alexander von Humboldt. Reinbek: Rowohlt.

Minguet, Charles. 1986. "Rómulo Gallegos à la lumière de Humboldt." Crisol 5 (octubre 1986). 47-49.

Miranda, José. 1962. Humboldt y México. México: UNAM.

Olivera, Otto. 1998. "Humboldt, Alexander von. 'Essai politique sur l'île de Cuba' (1807), 2 vols. París: Libraire de Gide Fils, 1826. XLVI-364 \& 408 págs." Viajeros en Cuba (1800-1850). Miami: Ediciones Universal.

Puig-Samper, Miguel Ángel (ed.). 2000. Alejandro de Humboldt y el mundo hispánico. La Modernidad y la Independencia americana. Madrid: Fundación Histórica Tavera.

Quesada Monge, Rodrigo. 1999. "Humboldt, Bolívar y Marx: encuentros y desencuentros." Casa de las Américas 216. 5-15.

1985. Le Robert. Dictionnaire de la langue française 9 tomos. París: Le Robert.

Rübe, Werner. 1988. Alexander von Humboldt. Anatomie eines Ruhmes. Munich:

Deutscher Kunstverlag.

Schleucher, Kurt. 1988. Alexander von Humboldt. Berlín: Stapp.

- 1984. Alexander von Humboldt. Der Mensch-Der Forscher-Der Schriftsteller. Darmstadt: Eduard Roether Verlag.

Schuchard, Barbara. 1999. "El análisis de la realidad económica y política de Cuba." Humboldt. Bonn: Inter Nationes. 41:126. 92-98.

. Scurla, Herbert. 1982. Alexander von Humboldt. Eine Biographie. Düsseldorf: Claassen. 